\title{
Hydrological Model for Decision-Making: Männikjärve Bog Case Study, Estonia
}

\author{
Oskars JAVA ${ }^{1}$, Marko KOHV², Asko LÕHMUS ${ }^{2}$ \\ ${ }^{1}$ Vidzeme University of Applied Sciences, Cēsu street 4, Valmiera, LV-4101, Latvia \\ ${ }^{2}$ University of Tartu, Ülikooli 18, 50090 Tartu, Estonia \\ oskars.java@va.lv, marko.kohv@ut.ee, asko.lohmus@ut.ee
}

\begin{abstract}
In order to support the conservation of bog ecosystem over its geographic range and its genetic diversity, marginal areas of lower quality as a result of damage or degradation which abut active raised bogs may need to be included, protected and, where practicable, regenerated. There are very few intact or near-intact raised bogs in Europe, except in Finland and Sweden where active raised bogs are the predominant mire complex type in hemiboreal and southern boreal regions (European Commission, 2013). Leaf area index is an important parameter as it emblematize vegetation. After the construction of drainage, bogs usually become overgrown with trees, the restoration of the ecosystem requires vegetation manipulation. There are many degraded bogs in Estonia and Latvia that have overgrown with trees, and this type of simulation model would help to calculate the right tree cutting intensity to reduce the impact of evaporation and interception of trees on the water balance of the bog, thereby contributing to the restoration of the bogs. This article describes the case study of Männikjärve's bog where system dynamics simulation model for decision-making, built in Stella Architect environment, was validated.
\end{abstract}

Keywords: Simulation Modelling, Hydrological Modelling, System Dynamics, Bog Restoration, Model Validation.

\section{Introduction}

After drainage work, with groundwater level decreasing, trees begin to grow faster and larger in volume, filling the previous bog area and its surroundings. The large volume of tree foliage, through the interception of rainwater, prevents it from reaching the ground because it evaporates back into the atmosphere. In addition, trees favor water absorption from the soil trough their roots further enhancing the drainage effect (Java, 2018). Those negative feedback mechanisms of drainage further enhance loss of open habitats that are important for many rare species.

Restoration of mire ecosystems reduces the negative drainage effect on biodiversity and ecosystem functioning both locally and across landscapes, because degraded raised bogs still capable of natural regeneration (habitat No 7110) often include other habitats such as natural dystrophic lakes and ponds (habitat No 3160), depressions on peat substrates of the Rhynchosporion (habitat No 7150) and/or bog woodland (habitat No 91D0) as components of the biotope complex (Evans, 2006). To hydrologically restore a degraded bog, it is necessary to fill up the drainage ditches and sometimes fell at least 
part of the afforested area. Restoration of peat-forming mires as carbon sinks for climate change mitigation should avoid flooding the sites but instead should establish a water table slightly below the peat surface to reduce unwanted methane emissions. By using input data collected at site, this simulation model could assist restoration projects of degraded bogs, because without simulation, it is hard to predict what the consequences of human action on the bog reconstruction will be.

Large scale mire restoration is one of the "low-hanging fruits" for climate change mitigation as natural bogs act as carbon sinks. This activity is currently in progress both in Estonia and Latvia. The first stage is to close the drainage systems but second, often most expensive and controversial, is (partial) removal of the tree cover. There are currently no generally accepted simulation or modelling tools that would allow beforehand assessment of the effects of the tree cutting. Such a tool would be very helpful in the mire restoration planning as it would guide tree removals to the most optimal places and amounts. A modelling approach would be an innovative and sustainable way of solving this problem.

Simulation models are increasingly being used to solve problems and to aid in decision-making (Sarget, 2011). System dynamic modelling makes use of computer simulation to generate the consequences for studying the dynamic behavior of the system (Martis, 2006), in this case bog ecosystem. Bog hydrological system is a complex system with many components, thus simulation modelling is a useful tool to observe how the elements that shape bog ecosystem interact with each other. As simulation model described in this article include leaf area index, some expensive vegetation measurements are not needed.

This research would hopefully make the model a useful tool in bog restoration projects, because it allow to predict the tree removal influence on the restored ecosystem.

This article is structured in sections starting with description of model inner parts, geographic area and model features. In results and discussion section sensitivity analysis on basis of which the model was calibrated is described, followed by verification based on statistical calculation. The last section describe conclusions and future work including perspective for the application of artificial intelligence technologies.

\section{Study area}

\subsection{Model structure}

The simulation model is designed to represent the movement of water in the bog hydrological system from water intake through the precipitation to the water output through interception, sublimation, evaporation, transpiration, lake outflow and overland flow. As in the dynamic system in the bog hydrological model, the flow of water from one stock to another takes place on the basis of a mutual mathematical causal relationship.

How user and modeler interact with the bog hydrological model, and inner parts of the model interacts with each other are shown in Figure 1. 


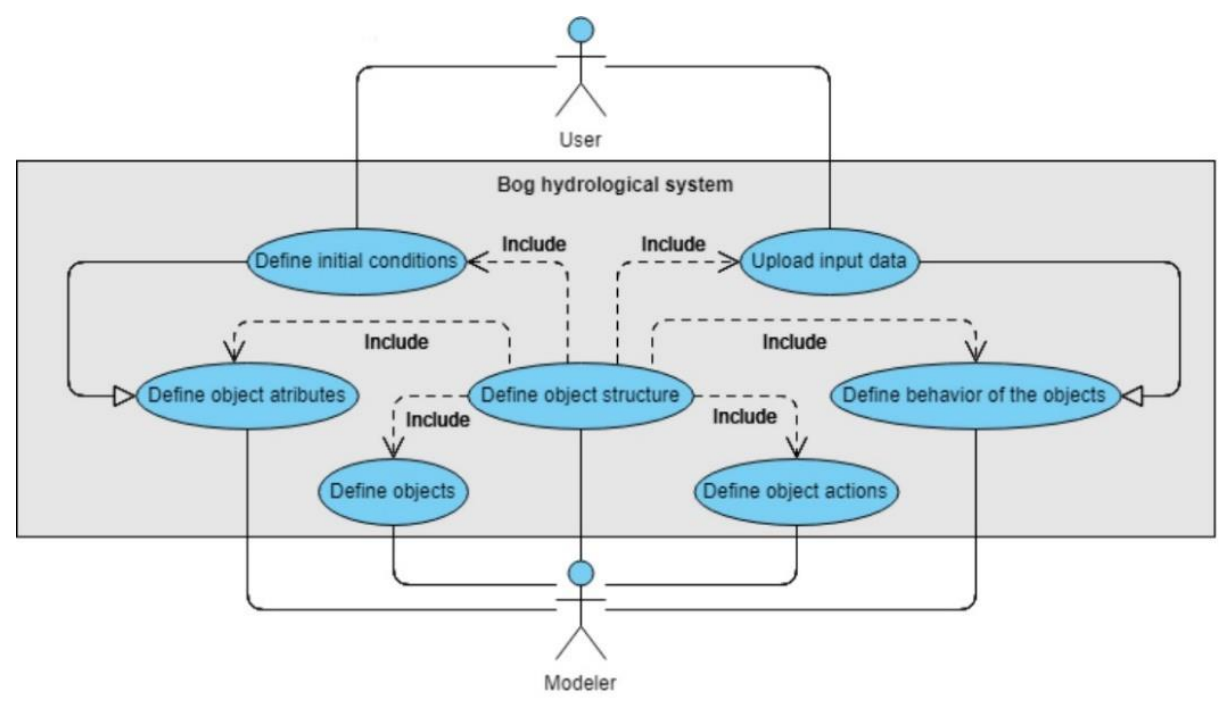

Fig.1. Internal steps of the bog hydrological model UML use case diagram (Java, 2020)

\subsection{Geographic area and its features}

The present Endla reserve was created in 1985 as an expansion of the previous smaller Endla-Oostriku mire reserve. It is located immediately south of the Pandivere Upland in east-central Estonia (Fig. 2). The Endla mire complex grew up in the depression of former Great Endla Lake. Several remnants of this lake still survive. The Endla mire system covers $\sim 25,000$ ha and contains several bogs separated by narrow rivers, and significant springs rise in the western part of the complex. The lakes, bogs, and springs are important sources of recharge for the Põltsamaa River. Among the bogs, Männikjärve has been investigated intensively since the early 1900s. Oblique views across the bog display overall patterns of hummock ridges, dwarf pines, hollows, and water-filled pools. In close-up oblique and vertical views, it is possible to identify individual small trees, moss hummocks, faint trails, small potholes, and other structures. Varieties of peat moss are distinct in their autumn coloration bright red, reddish orange, and greenish yellow. Color-infrared images emphasize active moss around the margins of pools (Aber, 2010).

Männikjärve bog, 176 ha in size, developed more than 9,000 years ago, the Boreal period, due to limnogenic terrestrialisation. The bog stage was reached in the Sub-Boreal time, 3,500 years ago. The maximum peat depth is 7.5 meter. Männikjärve bog has a typical East-Estonian convex with hollow-ridge and pool-ridge microtopes with a bogPine forest on the marginal slopes, see figure 3.3. The pools are approximately parallel and contour oriented, about halfway the highest point and the western bog margin. The eastern part of the bog was drained in the first half of the 20th century. In 1950, the hydrometeorological observation network of Tooma Mire Station was established at Männikjärve bog to monitor the water balance and microclimate of the raised bog. At this moment, Männikjärve bog is one of the most intensively studied mires in Estonia (Custers and Graafstal, 2005). 


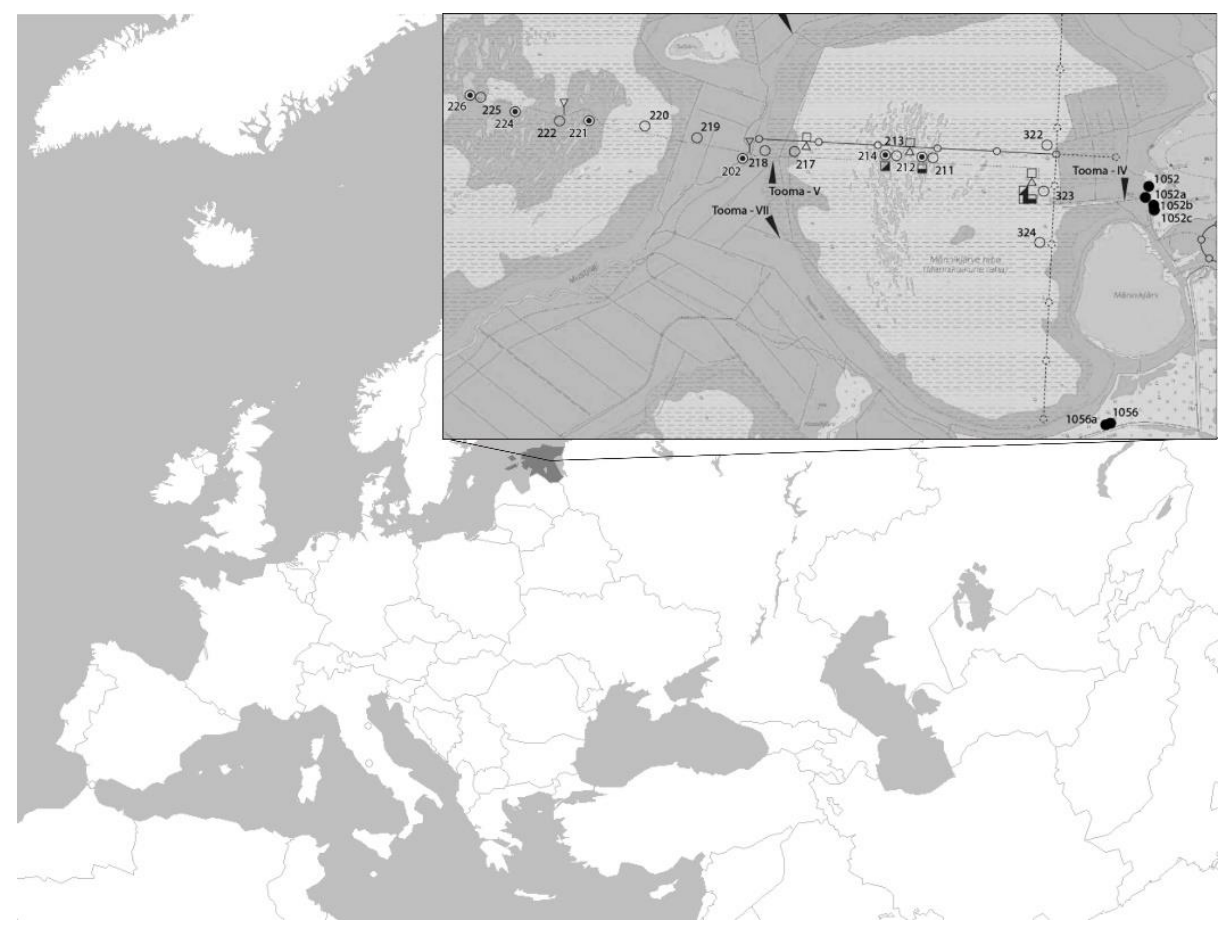

Fig.2. Study area Männikjärve bog in Estonia (Oosterwound et al., 2017),

(WikipediaHomepage, 2020)

\subsection{Input data}

To run the degraded bog system dynamics model it is necessary to have:

Meteorological data:

- Daily precipitation;

- Daily wind speed;

- Daily solar radiation;

- Daily air temperature;

- Daily relative humidity.

Geological data:

- Bog area and slope;

- Lake area and depth;

- Channel width, depth, length and slope;

- Peat layer, till layer and shale layer depth.

- Soil hydraulic properties:

- Peat layer, till layer and shale layer wetting front suction head;

- Peat layer, till layer and shale layer saturated hydraulic conductivity;

- Peat layer, till layer and shale layer saturated moisture content. 
Remote sensing data:

- Reflectance in near infrared band;

- $\quad$ Reflectance in red band.

Other data:

- $\quad$ Leaf distribution coefficient (Java, 2020).

Several groundwater measurement wells are located in the bog (Fig.2), but for model verification, a well number 222 located in the central part of the bog was selected. The required historical entry data were obtained from Tooma meteorological station, located $1.9 \mathrm{~km}$ from the well. The model uses Stella Architect software, which has a limit of 2500 data point, so the mean values of meteorological data are used for each day. The geological and soil hydraulic property data are derived from the Custers and Graafstal (2005) research.

Not all the input data is easy measurable, thus model parameter calibration is an important step to be taken in order to determine all the parameters needed to run the model.

\subsection{Output data}

As a result of this system dynamics model output data for each time step is generated, including:

1. Daily rain and snow interception;

2. Daily snow melting;

3. Daily snow cover evaporation;

4. Daily soil evaporation;

5. Daily tree stand transpiration;

6. Daily overland flow;

7. Daily soil evaporation;

8. Daily water infiltration in the soil;

9. Daily percolation in the till and shale layer;

10. Daily groundwater level;

11. Daily channel flow;

12. Daily lake evaporation (Java, 2020).

The most important parameter is groundwater level. By restoring the natural level of groundwater, it will be possible to prevent an intense overgrowing of areas with dwarf shrubs - favorable conditions will be created for development and existing of berries, mushrooms, various moss, lichens and other moisture loving populations and preservation of gathering places of human favorite nature goods - cloudberries, cranberries and mushrooms (Kampuse, 2019).

Other generated data rows may be useful during model calibration process to compare them with measured data, if one have measured it. 


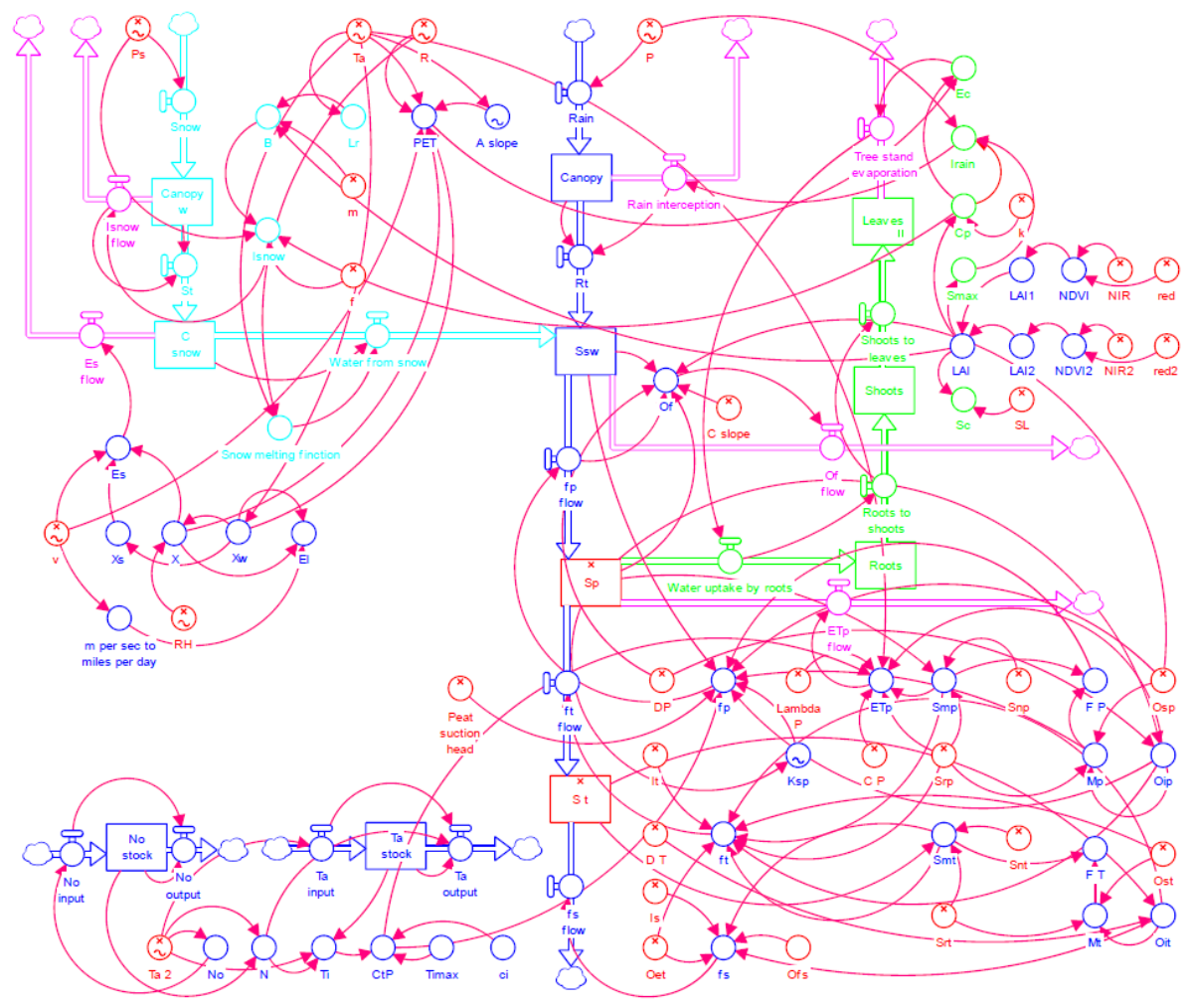

Fig.3. Visual representation of bog hydrological system dynamics model in Stella Architect environment (by the authors)

Visual representation of bog simulation model (Fig.3.) may look like conceptual model, but it is a functioning system dynamics model. The author sees it as the strong side of Stella Architect environment at the beginning of the bog study, because it is convenient to demonstrate it to decision-makers. It is easy for decision-makers to see how it is built and how water flows from one stock to another. If decision-makers are satisfied with the result, it is possible to replicate the simulation model in the Python code, which is more time-consuming but opens up the possibility of performing a simulation in a larger geographical range and display data in a grid.

\section{Results and discussion}

\subsection{Sensitivity analysis}

The first simulation model run was made not knowing exact coefficients, but determining them based on the information described in the scientific literature. As seen on the chart in the Figure 4 simulated groundwater level is trying to copy the path of the measured groundwater level, but is lacking precision especially during the wintertime when the groundwater level stays flat for a longer period. 


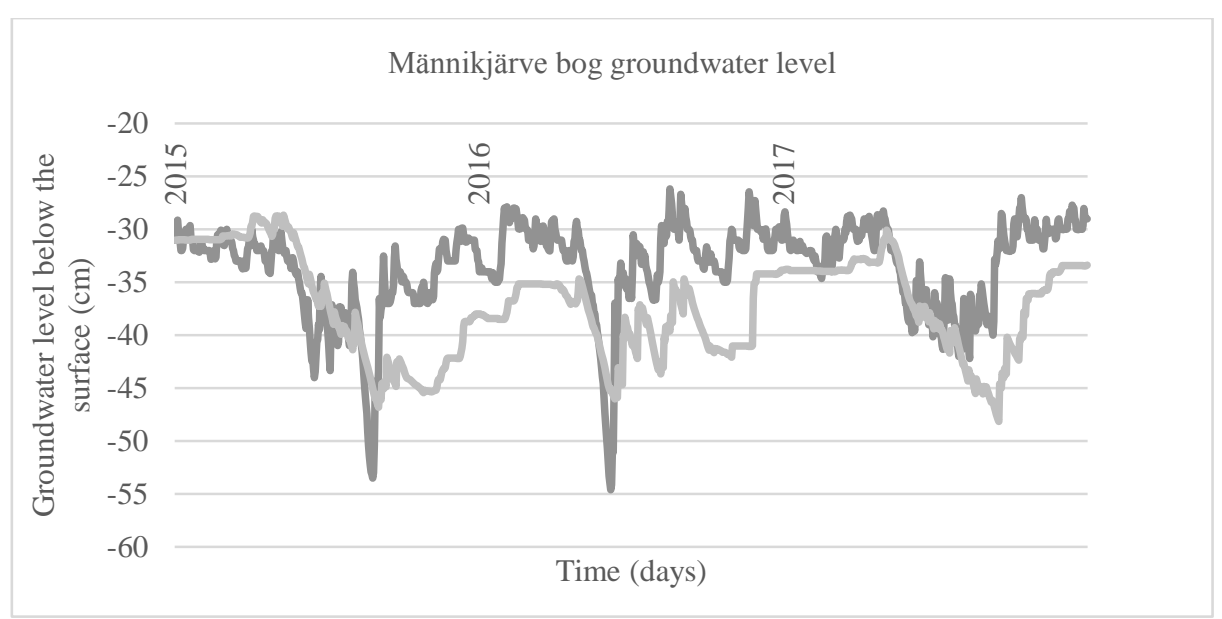

Fig.4. The bog hydrological simulation model output data after the first run using input data from Männikjärve bog. Dark line is the measured groundwater level; light line is the simulated groundwater level (by the authors)

After some more model runs, it was clear that there are two main equations, which are responsible for mismatches during the wintertime. One was water infiltration into the frozen soil and the other one was tree stand evaporation, because coniferous evaporate even during winter, which were not taken into account at the beginning. Both equation were modified and the simulated groundwater level started to fluctuate even during winter.

The analysis of parameter sensitivity is an established method for identifying and comparing the effects of changes in model parameter values on the model output (Pfannerstill et al., 2015), which was, accordingly, the first stage in the Männikjärve bog case study to determine how sensitive input parameters of the simulation model are and to verify the importance of collecting accurate input data and calibrate the coefficients.

The sensitivity analysis was firstly carried out for the coefficients, which are subject to calibration:

- Leaf distribution and inclination angle;

- $\quad$ Specific leaf storage;

- Snow interception coefficient;

- Evaporation constant of the peat;

- Maximum temperature point at which the peat layer surface is fully defrosted;

- Exponential coefficient describing the influence of temperature on soil defrosting.

After testing the sensitivity of the coefficients, the analysis was also carried out for individual measurable amounts as:

- Leaf area index;

- Peat suction head;

- Peat minimum water storage;

- $\quad$ Peat maximum water storage; 
- $\quad$ Till minimum water storage;

- Till maximum water storage;

- Peat saturated water content;

- Till saturated water content;

- Till effective porosity.

As expected, the greatest impact on groundwater level is for transpiration of peat. Based on impact on fluctuations in groundwater level, the next most sensitive parameters are vegetation-related parameters as leaf area index, leaf distribution and inclination angle, specific leaf area. This suggests that this simulation model may be a very valuable tool to perform more accurate calculations of cutting intensity before felling the trees.

\subsection{Calibration}

Following a sensitivity analysis, the model was calibrated to make the mathematical representation of the natural processes as accurate and close to the natural processes as possible. As all system dynamic models, bog hydrological simulation model as well need some time to warm up, which is why during the calibration process one extra year was added, which is not shown in the diagrams. Respectively, 2017 ends with a groundwater level $30 \mathrm{~cm}$ below surface, while 2015 begins with a groundwater level 30 $\mathrm{cm}$ below surface.

Spatially explicit and physically-based model approaches are often criticized because the estimation of model parameters is difficult and uncertainty at high resolution may diminish potential gains in prediction accuracy. Thus, efficient calibration of the models is difficult due to the spatially distributed nature of those models, showing, sometimes, a decrease in efficiency, compared to lumped models (Pérez-Sánchez et al., 2019).

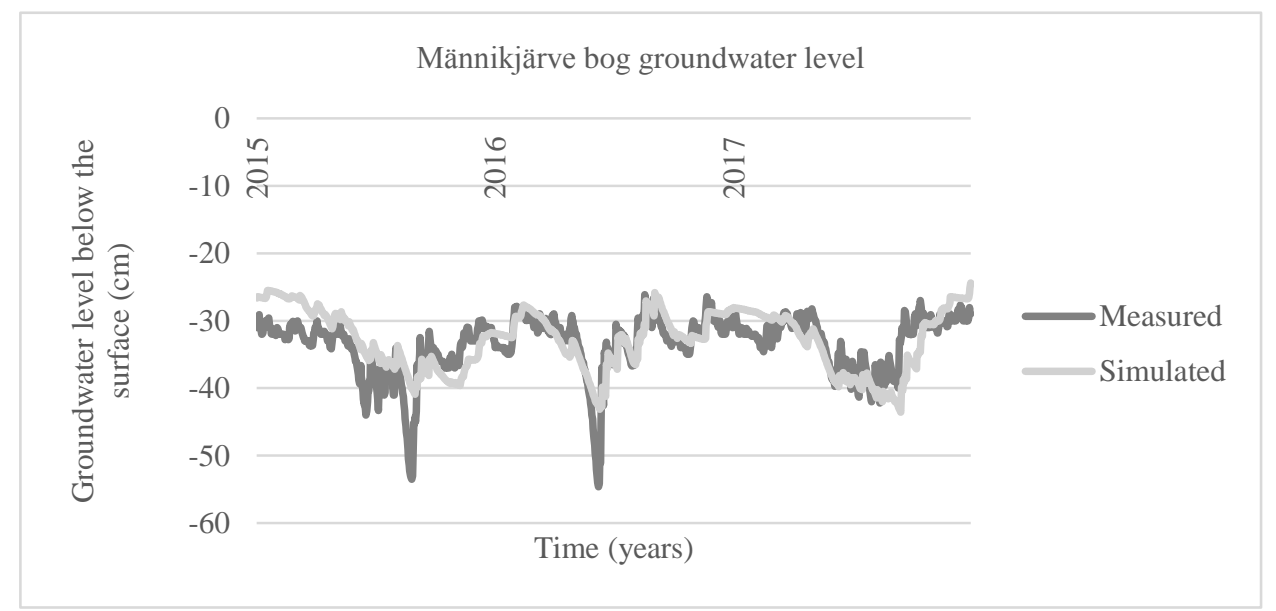

Fig.5. The bog hydrological simulation model output data after calibration using input data from Männikjärve bog (by the authors)

The conclusion after model calibration (Fig.5) is that it runs well, because the mean average error is 3.9 centimeters. The exceptions are two downward peaks in the summer of 2015 and 2016, where the difference from measured and simulated groundwater level 
is $11.9 \mathrm{~cm}$ and $13.1 \mathrm{~cm}$. Which is the main reason for these offsets, it is difficult to determine because the model consists of many building blocks that affect each other. In Estonia, the normal daily amount of solar radiation is $200-230 \mathrm{~W}$, but before those two peaks, radiation exceeded $250 \mathrm{~W}$ per day for more than ten days in a row in combination with very low wind speed from 0 to $1.6 \mathrm{~m} / \mathrm{s}$.

Given that global climate change is increasingly causing extreme weather conditions, the author considers that the use of machine learning algorithms should be considered to improve the simulation model, in order to allow for the identification of factors responsible for deviations in the output data in case of extreme weather condition and to adapt the equations.

\subsection{Validation}

The most important quantitative criterion is accuracy (Ha et al., 2018). To verify bog hydrological system dynamics model historical data validation method was used. As the main prerequisite for the recovery of a degraded bog is an appropriate level of groundwater, increased attention was paid to comparing the groundwater level data generated by the simulation model with the measured results. Mean absolute error is 20 $\mathrm{mm}$, root mean squire error (RMSE) is 1.049 , and mean absolute percentage error (MAPE) is 1.153 .

With confidence interval 0.95 and significance level 0.05 linear regression is 0.708 and R-squired regression is 0.5014 (Fig.6).

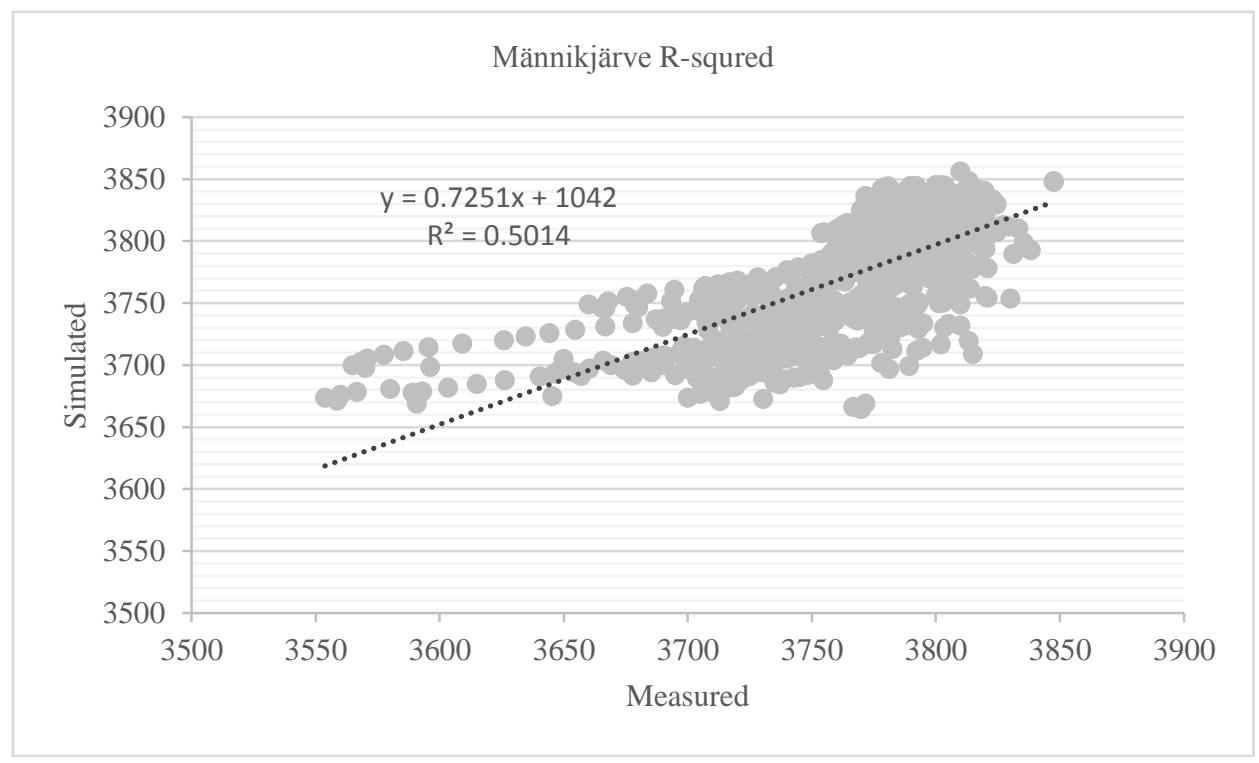

Fig.6. Männikjärve R-squired regression (by the authors)

Confidence interval point estimate with confidence coefficient 0.95 and significance level 0.05 is $3765 \mathrm{~mm}$ (measured), $3772 \mathrm{~mm}$ (simulated). Margin of error is 2,605 (measured), 2,667 (simulated) (Fig.7). 


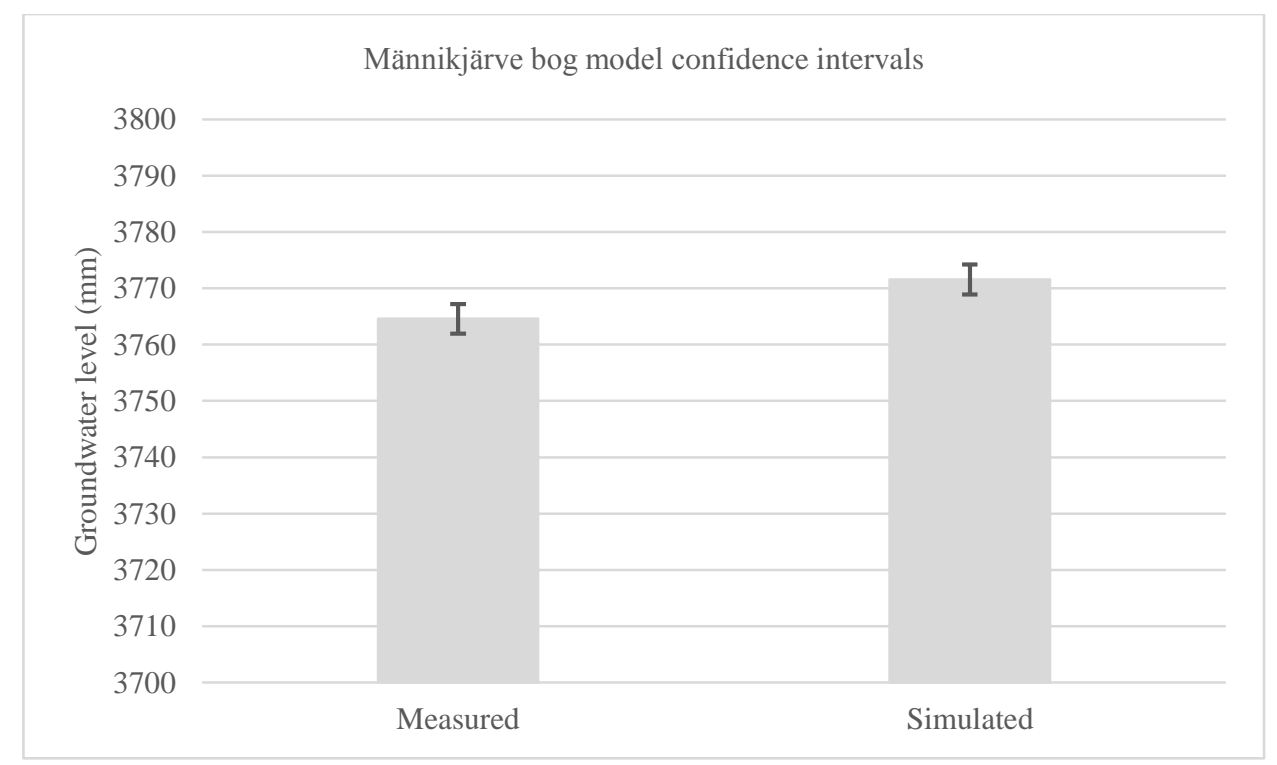

Fig.7. Männikjärve bog model confidence intervals (by the authors)

\section{Conclusions and future work}

As acknowledged by the co-authors of the article (geologist and biologist), there are currently no generally accepted simulation or modelling tools that would allow beforehand assessment of the effects of the tree cutting. The co-authors, as experts, assess this imitation model as valid, because it takes into account all causal relationships that affect the hydrological regime and generate accurate output data close to the measurements.

This simulation model include vegetation in the sensitivity analysis, thus some expensive measurements are not needed, making it potentially interesting for decisionmakers. To test what the model is capable of, it would be interesting to test it in a bog for which historical data are available before the bog restoration project and a sufficiently large dataset also after tree cutting.

As we are moving towards climate-neutral Europe, the issue of bog restoration is particularly pressing, because they are large carbon sinks. Bogs cover only $3 \%$ of the global land area, but have accumulated about one-third of the worlds estimated total soil carbon (Kiely et al., 2018).

Given that global climate change is increasingly causing extreme weather conditions, the author considers that the use of machine learning algorithms should be considered to improve the simulation model, in order to allow for the identification of factors responsible for deviations in the output data in case of extreme weather condition and to adapt the equations.

The author sees that the accuracy of this simulation model from R-squired 0.5014 would be possible to be raised if converted to the Python code. The Python code would allow the model to be connected with meteorological databases where information is available on shorter time steps than mean daily values. For example, if $20 \mathrm{~mm}$ of 
precipitation occurs during the day, the water gradually infiltrates in the soil, but if 20 $\mathrm{mm}$ of precipitation falls within one hour, the soil is unable to accumulate this amount of water in such short period and forms a surface runoff that has the potential to flood geographically lower areas. Therefore, more entry data points will allow the model to generate more accurate output data and decrease magnitude of error in extreme weather conditions.

Machine learning algorithms should be considered to improve the simulation model. Unsupervised learning methods can easily be used for sensor fault and anomaly detection (Oosterwoud et al., 2017). It is possible to use an artificial neural network to balance the effect of multiple environmental factors on the air temperature measurements (Yamamoto et al., 20117). It would allow to save money by using cheaper sensors for data collection on the field and make the use of simulation models a more accessible tool in decision-making practice.

Given the technological development of artificial intelligence using machine-learning weather forecasts, it will be possible to predict in the near future the effects of human activity on different fragile ecosystems in the long term.

\section{Acknowledgements}

This research was made under University of Tartu Dora Plus sub-activity 2.2 grant for international visiting doctoral students.

\section{References}

Aber, J., Marzolff, I., Reis, J.B. (2010). Wetland Environments. Small-Format Aerial Photography, 201-212

Custers, J., Graafstal, H. (2005) Characterization of the water flow in a pool-ridge microtope in a bog. A case study of Männikjärve bog, Estonia. 1-66

European Commission (2013). Interpretation Manual of European Union Habitats - EUR 28. European Commission DG Environment. 1-146

Evans, D. (2006). The Habitats of the European Union Habitats Directive. Biology and Environment, 106B (3), 167-173

Ha, J-H., Kim, Y-H., Im, H-H., Kim, N-J., Sim, S., Yoon, Y. (2018) Error Correction of Meteorological Data Obtained with Mini-AWSs Based on Machine Learning. Advances in Meteorology, 1-8

Java, O. (2020). The Specification of Hydrological Model Requirements for Bog Restoration. Baltic Journal of Modern Computing. 8(2020), 164-173, https://doi.org/10.22364/bjmc.2020.8.1.11

Kampuse, K. (2014) Groundwater level restoration works in Swan Island bog (in Latvian). Available at http://daba.gov.lv/public/lat/zinas/1921/

Kiely, G., Leahy, P., McVeigh, P., Laine, A., Lewis, C., Koehler, A.K., Sottocornala, M. (2018). PeatGHG - Survey of GHG Emission and Sink Potential of Blanket Peatlands. EPA Research, 1-35

Martis, M.S. (2006). Validation of Simulation Based Models: A Theoretical Outlook. The Electronic Journal of Business Research Methods, 4(1), 39-46

Oosterwoud, M., van der Ploeg, M., van der Zee, S. (2017). Variation in hydrologic connectivity as a result of microtopography explained by discharge to catchment size relationship. Hydrological Processes, 31(15), 2683-2699

Pérez-Sánchez, J., Senent-Aparicio, J., Segura-Méndez, F., Pulido-Velazquez, D., Srinivasan, R. (2019). Evaluating Hydrological Models for Deriving Water Resources in Peninsular Spain. Sustainability, 11, 1-36 
Pfannerstill, M., Guse, B., Reusse, D., Fohrer, N. (2015). Process verification of a hydrological model using a temporal parameter sensitivity analysis. Hydrology and Earth System Sciences, 19, 4365-4376

Sarget, R.G. (2011). Verification and Validation of Simulation Models. Proceedings of the 2011 Winter Simulation Conference, 183-198

Wikipedia Homepage (2010). Available at https://et.wikipedia.org/wiki/Fail:Europe_map_estoni a.png

Yamamoto, K., Togami, T., Yamguchi, N., Ninomiya, S. (2017). Machine Learning-Based Calibration of Low-Cost Air Temperature Sensors Using Environmental Data. Sensors, 1-16

\section{Authors' information}

Oskars Java received the master's degree in computer sciences in the field of Information Technology (System Analysis, Modelling and Design subsector) in year 2017. Author is proceeding $\mathrm{PhD}$ studies in the field of Information Technologies at Vidzeme University of Applied Sciences where he uses IT technologies to solve issues in the nature.

Marko Kohv is a researcher from University of Tartu, Department of Geology. His main research fields are wetland hydrology and monitoring.

Asko Lõhmus is a research professor and Chair of Natural Resources at the University of Tartu, where he is currently leading several projects on ecosystem restoration and management.

Received May 10, 2020, accepted May 16, 2020 as a reviewed conference paper 